\title{
Apuntes sobre Ricardo Palma y el español del Perú
}

\author{
Marco Martos Carrera \\ Academia Peruana de la Lengua \\ marcomartos9@hotmail.com
}

\section{Resumen}

Debido a la colonización lingüística y a la hibridación del lenguaje por su contacto permanente con las lenguas indígenas, el castellano es una lengua que ha ido cambiando con el tiempo, adquiriendo variaciones en cada región de América. En el caso del Perú, la imposición de una lengua en un territorio que tenía muchas otras, ha generado la aparición de peruanismos, incorporando muchos vocablos de origen nativo a la lengua general. La figura de Ricardo Palma es importante, no solo por su escritura literaria sino por su actitud de defensa cerrada del castellano andino y de la incorporación de nuestros vocablos al diccionario de la Real Academia Española en 1892.

Palabras Clave: Hibridación, lenguaje, peruanismos, Ricardo Palma, Real Academia Española.

\begin{abstract}
Due to linguistic colonization and language hybridization due to its permanent contact with indigenous languages, Spanish is a language that has been changing over time, acquiring variations in each region of America. In the case of Peru, the imposition of a language in a territory that had many others has generated the emergence of Peruvian idioms, incorporating many words of native origin into the general language. The figure of Ricardo Palma, is important, not only for his literary writing, but for his attitude of closed defense of the Andean Castilian and the incorporation of our words to the dictionary of the Royal Spanish Academy in 1892.
\end{abstract}

Keywords: hybridization, language, peruanismos(Peruvian idioms), Ricardo Palma, Royal Spanish Academy 
Marco Gerardo Martos Carrera, Escritor, poeta y periodista peruano. Es considerado uno de los principales representantes de la Generación del 60 en la poesía peruana. Presidente de la Academia Peruana de la Lengua, catedrático de la Universidad Nacional Mayor de San Marcos y ex decano de la Facultad de Letras y Ciencias Humanas de dicha casa de estudios. 
Los idiomas se desplazan por el mundo de diferentes maneras: por la cantidad de sus hablantes, por el prestigio social de una lengua o por la fuerza. Y ha sido esta última el motor de la presencia del español o castellano en las tierras americanas. Los conocedores de la poesía peninsular recuerdan bien algunos versos del poeta petrarquista español Hernando de Acuña, que sirvió a Carlos V y a Felipe II. Dirigiéndose al primero, escribió:
Al Rey Nuestro Señor
Ya se acerca, Señor, o ya es llegada
la edad gloriosa en que promete el cielo
un grey y un pastor solo en el suelo
por suerte a vuestros tiempos reservada;
ya tan alto principio, en tal jornada,
os muestra el fin de vuestro santo celo
y anuncia al mundo, para más consuelo,
un Monarca, un Imperio y una Espada;
ya el orbe de la tierra siente en parte
y espera con toda vuestra monarquía,
conquistada por vos en justa guerra,
que, a quien ha dado Cristo su estandarte,
dará el segundo más dichoso día
en que, vencido el mar, venza la tierra. (Polt, 1962: 220)

Un monarca, un imperio y una espada era el sueño imperial que se cumplió en América, mejor que la propia España. La lengua viajaba en el cañón de los arcabuces y en la punta de las dagas. Las huestes de Pizarro y Almagro traían un idioma que todavía no había fijado definitivamente sus estructuras, y que estaba sumando un vocabulario de distintos orígenes. Algo de 
lo que ellos portaban, un léxico que luego se fue modificando y desapareciendo en alguna proporción se quedó en algunos lugares vivo y actuante, por aquel fenómeno que Ferdinand de Saussure llamó espíritu de campanario. Así, palabras como enantes (hace un momentito) o pezpita (coqueta) se quedaron entre nosotros. Solo en años recientes ha disminuido el uso de enantes en la lengua culta peruana, mientras que pezpita sigue siendo de uso corriente en el habla del norte, en la región de Piura, donde se pueden escuchar frases como esta: "Esa pezpita les pela las muelas a todos los hombres que pasan." No está de más recordar que la mujer aborigen que mereció la atención afectiva de Francisco Pizarro era apodada precisamente "la pezpita". La palabreja aparece en el Diccionario de la lengua como sinónimo de "pizpita" o "lavandera blanca", un ave de la región de Extremadura que luce una cola de múltiples colores.

El castellano que vino a América no vino de una vez por todas, sino que siguió viniendo en carabelas a lo largo de tres siglos, y ahora mismo a través de las ondas de la modernidad. Solo que el viaje no es de un solo lado, sino que es de ida y vuelta, y el castellano de los americanos tiene una vigorosa presencia en el conjunto de la lengua y eso significa que las lenguas que hallaron los españoles sobre los territorios que invadían, influyen primero sobre el español americano y después sobre el conjunto de la lengua. La lengua que hablamos y que escribimos es propiedad de todos los hablantes. El secreto de su fuerza es que tiene una estructura inamovible, una sólida sintaxis compartida por todos los hablantes, desde la época de Cervantes, y a ello debemos agregar otra circunstancia demostrada: compartimos también un noventa por ciento del vocabulario y el otro diez por ciento lo aprendemos sin fatiga, cuando lo necesitamos, en cada lugar que llegamos.

Ángel Rosenblat imaginó, o supo, la pequeña historia de un turista español que llega a México y lee un cartel que dice: 
"Se prohíbe a los materialistas estacionarse en lo absoluto" y se queda perplejo imaginando que la especulación filosófica ha llegado a los municipios, para descubrir más tarde que los mexicanos llaman "materialistas" a los transportistas porque trasladan materiales. Días más tarde, un chilango, es decir, un habitante de la capital, le dice esta frase enigmática: "Lo invito el sábado a comer en la casa de usted". Solo después de un rato de perplejidad, pudo descubrir que "la casa de usted" es la casa, en México, del que está hablando. Al llegar a Colombia, este infatigable español pudo descubrir que ahí "tinto" no es un vino como en Madrid o Lima, sino un café. Y que esos pequeños promontorios de cemento, las gibas españolas que dificultan la marcha de los autos en la calle, se llaman "policías acostados". Este turista de haber llegado al Perú se habría sorprendido también con el nombrecito nuestro: "rompemuelles".

Y aquí viene una cuestión central que nos concierne a todos los americanos que estamos en el orbe hispano: culturalmente, ¿quiénes somos, qué representamos? Muchos han reflexionado estos temas, pero un estudioso que ha dado una respuesta al mismo tiempo global y específica es la que ofrece el cubano Roberto Fernández Retamar en su texto Calibán (Concepción, 1998) y en otros escritos que ha ido produciendo a lo largo de décadas. Calibán es el americano que aprende una lengua metropolitana y que generalmente no tiene una lengua indígena propia con la que expresarse. No representa casi nunca a todos los individuos que tienen la lengua indígena como materna, pero sí a los individuos que tienen un idioma que fue colonizador y que de alguna manera se oponen al discurso dominante. Para Retamar, Calibán es un símbolo de la colonización lingüística, pero también del aprendizaje del lenguaje colonizador y, consiguientemente, del habla defectuosa y balbuceante, de la segregación de los que no tienen un dominio de la lengua, y de la hibridación del lenguaje colonizador en contacto permanente con las lenguas indígenas. Hay un escritor peruano, Efraín 
Miranda, que ha expresado, con palabras de la lírica, esta tensión idiomática:

La gramática española cuelga desde Europa

sobre mis Andes,

interceptando su sincretismo idiomático.

Sus grafías y fonemas atacan con los caballos

y las espadas de Pizarro.

Mi lenguaje resiste, se refugia, lo persiguen,

lo desmembran.

En tantos siglos de guerra intercultural

todas las vallas hemos perdido.

Ellos tienen todos los elementos a su alcance:

y sus soldados intelectuales;

los nuestros, nada, un agrupamiento, pasivo

al modo tupacamaru segundo.

En mi choza ha caído la mano perdida del Manco de Lepanto

con vidrios, ácidos, alfileres

que contorsionan mi lengua

y sangran mi boca ${ }^{1}$.

Sin duda, de este conflicto cultural, que Miranda expresa con rotundidad en un castellano standard, surgen múltiples caminos para entender la cultura del Perú. Miranda expresa en el siglo XX un hecho que viene desde el siglo XVI, la imposición de una lengua en un territorio que tenía muchas otras. En ese contacto de lenguas, la lengua vencedora no deja de tener las huellas de aquellas con las que comparte el territorio, como el quechua, el aimara y las cuarenta lenguas amazónicas registradas, e incluso de aquellas que desaparecieron en poco o mucho tiempo como

I Poema en: http://wpqsdossier.blogspot.pe/2008/1 l/poesia-de-efran-miranda.html 
el sec, el tallán, el lenguaje de Olmos, el culle, el mochica. Y ese es el castellano que hablamos, nuestra lengua franca en todo el territorio nacional. Es un castellano andino que influye la lengua general y que ha conseguido incorporar muchos vocablos nuestros al marco del español americano y a la misma lengua general con palabras como "papa" o "cancha", que se encuentran y se dicen en todos los rincones donde se habla castellano.

A lo largo de los siglos ha habido, y ahora mismo hay, distintas posibilidades en el manejo de la lengua española. Sin duda, el Inca Garcilaso es el primer modelo literario de un peruano que domina cabalmente la lengua castellana y que se expresa de manera alquitarada en un lenguaje de marca renacentista. Así mismo, a pesar de algunos estudios lingüísticos que aseguran aparentes descuidos u olvidos que el Inca tuvo de la lengua quechua, la opinión mayoritaria, señala que el Inca tuvo un conocimiento de detalle de la estructura de la lengua aborigen que funciona como sustrato en su castellano impecable. Literaria e históricamente, Garcilaso es el primer representante del castellano hispanoamericano digno de mención. Y esa es la línea en la que se colocan varios de los mejores escritores nuestros que funcionan como modelos. Así es Ricardo Palma, emblemático, no solamente por su escritura literaria, sino por su actitud de defensa cerrada del castellano andino. Muchas veces nos quedamos en lo anecdótico cuando nos referimos a su enfrentamiento con la Real Academia Española en 1892, a propósito de la incorporación de vocablos nuestros al diccionario de la corporación. Palma es sin duda un lingüista intuitivo que se adelantó en muchas décadas a algo que es común, el derecho de cada hablante a hablar la lengua que aprende desde niño, de la manera que la ha heredado. Es moneda común entre los lingüistas, reconocer que en las lenguas regionales, de las provincias, los países o los continentes, viven simultáneamente la lengua general standard y las lenguas particulares. De manera 
que es legítimo y pertinente hablar como sabemos. Y eso Palma lo tenía muy conocido y era su bandera de lucha. La creación de la Asociación de Academias de la Lengua Española en México (1951), merced a una iniciativa del presidente mexicano Miguel Alemán, señala de manera significativa que el poder sobre la lengua tiene que ser compartido entre todos los hablantes. Y la aparición del Diccionario de Americanismos en 2010, el DA, con la misma asertividad que el DEL, el Diccionario de la Lengua, que antes se llamaba DRAE, es señal de que se camina en la dirección correcta. Nuestros escritores de fuste se expresan siempre en un castellano americano. Un lingüista español, radicado mucho tiempo en Piura, Carlos Arrizabalaga, ha estudiado con minucia los peruanismos que utiliza Mario Vargas Llosa y los ha señalado con toda precisión. En sus primeros años de escritor, estos peruanismos abundan y poco a poco van disminuyendo, lo que es natural por los frecuentes cambios de residencia del novelista y tal vez también, añadimos, por los lectores que tiene en mente. Sin embargo, añadimos, en sus últimas novelas, El héroe discreto y Cinco esquinas, las voces del Perú vuelven a reaparecer de manera significativa. César Vallejo, que nos representa tan bien en el mundo de la poesía, tuvo una conciencia clarísima de su manejo de la lengua en toda su actividad literaria; como Palma o como Garcilaso, conoce bien las estructuras del idioma, habla y escribe en el castellano del Perú, como cuando dice:

Fue domingo en las claras orejas de mi burro, de mi burro peruano del Perú, perdonen la tristeza.

O cuando dice, presumiblemente dirigiéndose a lectores españoles:

Así se dice en el Perú, me excuso².

2 Poema en: http://www.poesi.as/cv30005.htm 
Imagino que para los correctores es una delicia leer los libros de autores de estas características. Y cuando trabajamos en las imprentas libros de naturaleza no literaria, protegidos por nuestro conocidos diccionarios, la pasamos bastante bien. El problema viene con los que escriben diferente y que merecen el mismo respeto que los primeros. Son los rebeldes, con causa o sin ella. ¿Qué hacer? ¿Cómo editar a Felipe Guamán Poma de Ayala? No sé cabalmente cuál es la respuesta justa, pero me parece pertinente el trabajo de Carlos Araníbar, quien presenta dos textos simultáneamente, para satisfacer a todo tipo de lectores. Y que pone especial atención a los dibujos de este autor que son una maravilla, isí señor! Estamos lejos de sostener, como alguna vez lo hizo Raúl Porras Barrenechea, de que este autor andino tenía "una jerigonza bárbara". Pensamos más bien que se trata de un creador poderoso, dueño de una escritura intermedia, un embrión de una lengua que no llegó a crearse, "el peruano", como sí ocurrió en Haití con el créole, que se ha convertido en lengua nacional de ese país.

En el siglo XX, otro autor, Gamaliel Churata (Arturo Peralta), con su Pez de oro intenta un camino similar. Churata es un claro ejemplo de un hombre de tres culturas; pertenece, como diría Rodolfo Hinostroza, al extremo Occidente, tiene un conocimiento pertinente de la tradición europea y se maneja con solvencia en el quechua y el aimara. Con alguna preponderancia del castellano, hace una mixtura lingüística difícil de entender por los legos e incluso por los entendidos. Editarlo sin errores es tarea descomunal. Algunos quieren añadir a José María Arguedas a este grupo mixturero. Sinceramente no me parece. Arguedas es literalmente un maestro, con un dominio superior de la lengua castellana y con un conocimiento profundo de la lengua quechua y se maneja con solvencia en los ensayos y en los libros académicos. Su castellano es andino peruano de gran hermosura. La mano que escribe es la de un gran conocimiento de la lengua, aunque muchas veces, como ocurre en su célebre 
novela El zorro de arriba y el zorro de abajo, sus personajes se expresan en un castellano callejero, popular, trufado de voces quechuas, e inclusive con interferencias sintácticas de ese idioma. El autor se cuida muy bien, es un erudito, un doctor, que jamás se confunde con sus personajes.

Un caso especial del manejo de la lengua es Manuel González Prada, rebelde parcial en la escritura postulaba, como Juan Ramón Jiménez, el uso escritural de la "j" en palabras como "página". Esta pequeña rebeldía no llegó a ser sistematizada. El ilustre escritor pensaba que el castellano del Perú debía ser influido por el alemán, inglés, francés, italiano y dejaba de lado la poderosa tradición de la lengua indígena. Sin embargo, contradictoriamente, pensaba que la esencia de la nacionalidad se hallaba en las estribaciones del Ande. Creo, sinceramente, que González Prada llevó al campo de la lengua sus postulados anarquistas. Y naturalmente no fue ajeno a los debates de su época, en los que participaron ilustres intelectuales y gramáticos como Andrés Bello, Domingo Faustino Sarmiento, Rufino José Cuervo, Rubén Darío y su propio antagonista, Ricardo Palma. Todo hace pensar que no tuvo una posición definitiva sobre el tema. Es curioso, pero en esta materia del lenguaje, el nacionalista es Palma y el extranjerizante es González Prada, y es que su visión sobre la historia del Perú es radicalmente pesimista. Piensa que en nuestro país, excluyendo a los europeos y al cortísimo número de blancos nacionales o criollos, la población se divide en dos fracciones muy desiguales por la cantidad: los encastados o dominadores y los indígenas o dominados. Cien o doscientos mil individuos se han sobrepuesto a tres millones. Su visión sobre la literatura peruana y española es desoladora, considera que entre nosotros todo lo bueno y lo malo ha sido imitado, que el Perú no cuenta con un literato que por el atrevimiento y el caudal de sus ideas se levante a la altura de los escritores europeos y que fuera de Cervantes ningún escritor español disfruta de popularidad en Europa. Considera que es difícil imaginar lo que habrían realizado 
un Góngora, un Lope de Vega, un Quevedo o un Calderón si en lugar de vivir encadenados al Dogma hubieran volado libremente o seguido el movimiento salvador de la reforma.

Respondemos los decires de González Prada, como corresponde a los tiempos que corren, con moderado optimismo. Tuvo mucha fortuna el Perú al tener en sus principios como nación a un escritor como el Inca Garcilaso, un verdadero milagro de la escritura, una pera del olmo, como diría Octavio Paz, fenómeno que no se repitió en otra nación del orbe hispano americano en esos años. Fue también positivo el hecho, aunque casi desconocido en su tiempo, que apareciese un escritor como Felipe Guamán Poma de Ayala con su lengua peculiar que marca el deseo de los Calibanes, en voz de Fernández Retamar, de apoderarse de la lengua de los conquistadores. La legión de imitadores que hubo durante el virreinato cumplió sin duda un papel importante, preparó la originalidad definitiva de una tradición. En esos siglos, rescatamos las voces originales de Pedro Peralta y Barnuevo y de Juan de Espinosa Medrano, el Lunarejo. Y entrando al siglo XIX, son precisamente los dos antagonistas, Manuel González Prada y Ricardo Palma, los protagonistas de la originalidad literaria peruana. Hubieron de pasar cuatro siglos para que nos surgiese un nombre de dimensión universal, César Vallejo. Su poesía tiene tal calidad e intensidad que es comparable a la de los mejores escritores del siglo de oro, Quevedo o Góngora, y no cede en potencia a la de ninguno de los más grandes poetas contemporáneos, sean estos Eliot o Pound, o Ungaretti o Quasimodo o Montale. Ningún autor americano, en el siglo veinte, en lengua española, ha expresado mejor el conflicto cultural de nuestras sociedades que José María Arguedas. Y Mario Vargas ha sabido llevar las características del castellano del Perú a todo el orbe hispano. La obtención del premio Nobel de Literatura en 2010 señala para él y para nuestra forma de hablar y escribir, un nivel de difusión nunca alcanzado antes en todo el mundo. 
Pero hasta un premio Nobel necesita de los ojos diligentes de los correctores, lo expresó de manera simbólica Jorge Ninapayta, el corrector y escritor que escribió el cuento "García Márquez y yo", quien imagina a un editor que corrige en los talleres la novela Cien años de soledad y descubre, en una segunda lectura, que en algún lugar falta una coma, la coloca y luego con alegría puede comprobar que su coma es respetada por el autor y continúa apareciendo en todas las ediciones. Se cuenta, de manera graciosa, que Mario Vargas Llosa leyó un artículo que se titulaba "Cincuenta errores de Vargas Llosa" y en lugar de incomodarse con el autor de esa nota, Marco Aurelio Denegri, comentó a su editora: "Contrátelo como corrector". Los autores, inclusive los que más saben de ortografía y de sintaxis, siempre necesitan de correctores. Seis ojos, aparte de los míos, han vigilado estas cuartillas para no decir dislates ante un lector tan ilustrado.

\section{Bibliografía}

Cornejo Polar, A. (1989). La formación de la tradición literaria en el Perú. Lima: Centro de Estudios y publicaciones.

Cornejo Polar, A. (2003). Escribir en el aire. Ensayo sobre la heterogeneidad sociocultural en las literaturas andinas. Lima: Centro de Estudios Literarios Antonio Cornejo Polar.

Garatea, C. (2010). Tras una lengua de papel. El español del Perú. Lima: Pontificia Universidad Católica del Perú.

Fernández Retamar, R. (1998). Todo Calibán. Concepción: Cuadernos Atenea.

Garcilaso de la Vega Inca (1971). Comentarios Reales de los Incas. (Edición, índice analítico y glosario de Carlos Araníbar). México: Fondo de Cultura Económica. 
González Prada, M. (2009). Ensayos 1885-1916. Edición, introducción y notas de Isabelle Tauzin Castellanos. Lima: Universidad Ricardo Palma.

Guamán Poma de Ayala, F. (2015). Nueva crónica y buen gobierno. Lima: Biblioteca Nacional del Perú.

Lienhard, M. (1992). La voz y su huella. Escritura y conflicto étnico cultural en América Latina 1492-1998. Lima: Editorial Horizonte.

Miranda, E. (1978). Choza. Lima: Empresa Editora Humboldt.

Palma, R. (2003). Papeletas lexicográficas. Lima: Academia Peruana de la Lengua y Universidad San Martín de Porres.

Polt, J.H.R. (1962) Una fuente del soneto de Acuña «Al Rey nuestro señor». En: Bulletin Hispanique, tome 64, N³-4. Consultado en: https://www.persee.fr/issue/hispa_0007-4640_1962_num_64_3

Rivarola Rubio, J. L. (1985). Lengua, comunicación e historia en el Perú. Lima: Lumen.

Vallejo, C. (2014). Obra poética. (Prólogo y notas de Marco Martos). Lima. 